\title{
Low Cost Safety Countermeasures for Improving Passing Opportunities in Congested Two Lane Two-Way Highways
}

\author{
D. R. C. Dassanayake
}

\begin{abstract}
Major operational problems associated with two lane two-way roads are speed differences between fast and slow moving vehicles and turning delays of vehicles. The unique operational characteristic of two lane highways is that overtaking is only possible when there is a gap in the opposing traffic lane. When the volume increases the passing demand increases rapidly while the gaps in the opposing traffic lane decline and thus reduce the passing capacity. The imbalance between passing opportunities and passing demand causes frustration among drivers leading to fatal crashes. This is considered to be a serious safety issue in congested two lane two-way highways. Low cost safety counter measures in congested two lane two-way highways have become effective and popular in many countries. Amongst them, passing lanes and climbing lanes play a major role. Application of different countermeasures is discussed. Some of the experiences and examples from New Zealand were elicited to describe the topic.
\end{abstract}

Keywords: Two lane two-way highways, Operational problems Safety countermeasures.

\section{Introduction}

Major operational problems associated with two lane two-way roads are passing delays due to speed differences between fast and slow moving vehicles and turning delays. Road sections with comfortable horizontal and vertical alignments and with low traffic volumes present less operational difficulties. But in reality this situation exists seldom. Geographic conditions of different zones do not permit smooth vertical and horizontal alignments. Particularly Sri Lanka has a very challenging geography where road designers have to work within many constraints.

Furthermore, ribbon development along Highways, social problems, political influences etc. make the road design task more complex.

There are distinct needs of motorists, for instance trips are generated by needs arising from office transport, public transport, goods transport, recreational activities etc. Different. purposes need different types and sizes of vehicles to be used in roads. The main causes for operational problems are the diversified needs of drivers, a variety of vehicle types moving on the road and the constraints in the road geometry.

In two lane two way highways speed differences are greater due to several factors.
They are, presence of heavy vehicles in the main traffic stream, local traffic, road geometry, driver characteristics etc. Higher the speed differences in vehicles in two lane highways, higher the demand for passing. When there is an imbalance between supply and demand for overtaking, driver frustration occurs. Platoon build up would be common when the headway vehicle is slow and in the absence of passing opportunities. As flow increases platoons get longer and slower. Generally, it is accepted that a driver can tolerate no more than $\mathbf{3}$ minutes following a platoon before getting in to frustration.

Consequences of driver frustration cause serious safety problems, where drivers take dangerous manoeuvres leading to crashes. Therefore, designing two lane roads should not only be limited to traditional geometric design criteria, but also should consider safe passing opportunities.

There are several countermeasures that can be applied to improve passing opportunities in two lane two-way roads. They are, namely, passing lanes, climbing lanes, turnouts, shoulder driving, shoulder used sections, short four lane

Eag. D. R. C. Dassanajake, C.Eng FIE(SL). MIE Aust, MICE BSc.Eng(Morntuwn), MEng.Const.Mgt (Moratuwn), MEng St.Thansportation (Auctland), Resident Englneer, Pandurn - Inglniyn Rond ICB component of Road Network Imprevement Prolect. 
sections, turning improvements for intersections, localised realignments, signs and markings etc. Road designers need to carefully evaluate the specific requirements of a road segment before deciding the most suitable application.

Counter measures described in this paper are not meant only for new roads but also for existing two lane two-way highways. These solutions could be applied on existing roads in order to improve operational problems. These are widely being adopted in existing rural state highways in New Zealand and other developed countries. Implementation of such improvements is undertaken where justified by cost benefit analyses.

Economic growth of a nation is underpinned by the existence of robust infrastructure asset systems. Transport infrastructure assets have a major share in supporting economic growth. Land transport systems in developed economies have balanced the access function and mobility function in their road net works.

Sri Lankan authorities have seemingly recognized that there is a greater mismatch in mobility function and the access function of our road network to cater for development strategies. As a result, major intercity expressways and ring road projects are underway. Some of them are already in the construction stage and a few are still in the planning or design stage. The author believes the discussion of the subject is timely as engineers need to articulate to different operational problems in two lane two-way highways.

\section{Operational Issues}

\subsection{Operational Characteristics of Two Lane Highways}

The unique operational characteristic of two lane two way highways is that overtaking is only possible when there is a gap in the opposing traffic lane. Therefore, unlike in multilane roads, the flow in one direction of a two lane two way highway influences the flow in the opposing direction. When the volume increases the passing demand increases rapidly while the gaps in the opposing traffic lane decline and thus reduce the passing capacity.

\subsection{Level of Service}

Traffic operations in two lane highways could be characterised by Percent Time Spent on Following ( PTSF) and Average Travel Speed (ATS). Those two parameters are used to determine the Level of Service (LOS).

PTSF increases with the increase of demand flow. Under ideal conditions, variation of PTSF is shown on figure 1

Under ideal conditions, capacity of a two lane two way highway is approximately 2800 Passenger Car units Per Hour (PCPH). With the increase of demand flow, ATS reduces from $100 \mathrm{~km} / \mathrm{h}$ to approximately $80 \mathrm{~km} / \mathrm{h}$ at 2800 (PCPH). At this stage, the facility has reached its full capacity. Further increase of demand flow rate would result in a reduction of ATS and the actual flow through the road section considered. This is shown in figure 2.

\subsection{HCM procedure}

Highway Capacity Manual (HCM, 2000) identifies Average Travel Speed (ATS) and Percentage Time Spent in Following (PTSF) as the two major determinants of Level of Service (LOS).which is a measure of the service quality of a facility. These two parameters are evaluated under base conditions and corrections are applied to mirror the actual conditions. Base conditions are [5]:

- lane width equal to or grater than $3.6 \mathrm{~m}$;

- clear shoulder wider than $1.8 \mathrm{~m}$;

- no 'no passing' zones;

- all passenger cars;

- no impediments to through traffic; and

- level terrain.

Studies have shown that at higher speeds, when drivers observe objects closer to the road edge they tend to slow down their vehicles. In addition, drivers show a propensity to shy away from the road side object when they are driving fast. The minimum distance from the road edge to a road side object that has no effect to motorists is termed as shy line offset [3]. Thus the overtaking task becomes comfortable when there are wider traffic lanes and clear shoulders. 


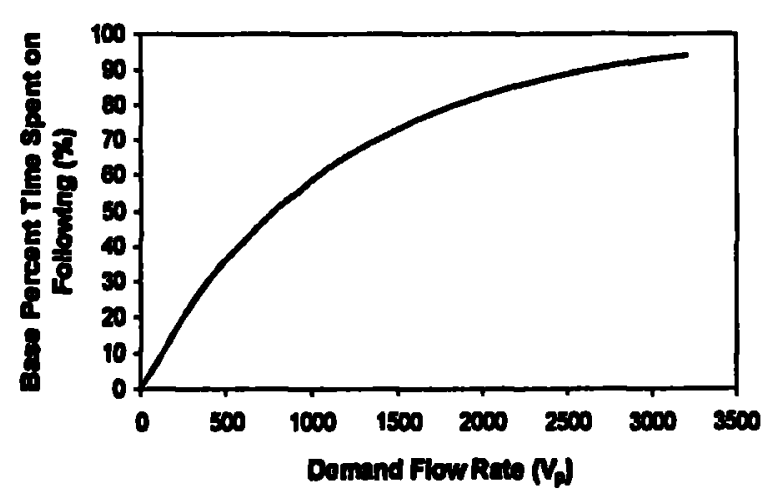

Figure 1. Relationship between Delay and Flow Rate

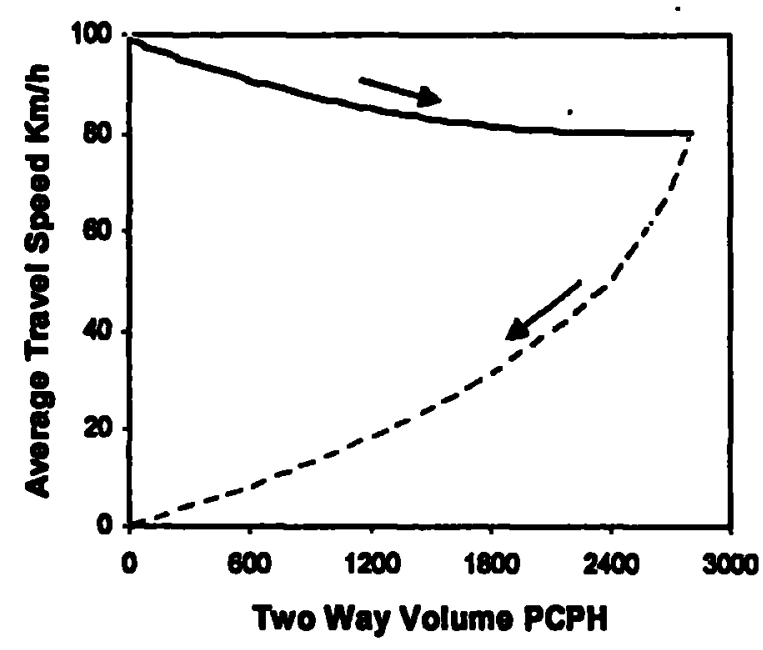

Source: Jolin Morrall,2003

Figure 2. Relationship between Average Speed and Flow Rate

Passing capacity is influenced by the geometric features of the facility and environmental factors. Geometric features of a road that affect the visibility of a motorist are horizontal curves and vertical curves.

Composition of the heavy vehicles in a traffic stream is another factor that influences the flow of a two lane highway segment. Average velocity in roads characterising higher composition of heavy vehicles is lower. Presence of heavy vehicles is addressed by considering percentage of different categories of heavy vehicles and their Passenger Car Equivalent factor (PCE) in capacity analyses.

Existence of at grade intersections, railway crossings etc. reduce the flow and the overtaking capacity considerably.

A complete procedure for operational analysis is beyond the scope of this article and is given in the HCM, (2000).

\section{Major Passing Improvements}

Major passing improvements are considered to be the addition of passing lanes, climbing lanes and short four lane sections. Major passing improvements are justified for roads where traffic volumes are reasonably high or of strategic importance.

\subsection{Passing Lanes}

Passing opportunities in two lane highways depend on the sight distance and the gaps in the opposing vehicle stream. When opposing traffic volume increases the gaps will be reduced. In high traffic volume situations, there is no significant gain in the passing opportunities even if the sight distances are improved by realignments. In such situations auxiliary lane would be a better alternative in improving safe passing opportunities. Apart from this, passing lanes reduce the total travel time. Introduction of passing lanes in a two lane highway will create a sense of assured journey time among road users. Provision of auxiliary lanes at regular spacing often leads to greater improvements in overall traffic operations than even major alignment improvements [1]. Definitions of passing lanes are given as follows.

"Additional parallel auxiliary lanes provided on two lane highwouys for exclusive purpose of inproving passing opportunities [8]."

"An auxiliary lane including diverge and merge tapers that is provided for slower vehicles to allow them to be overtaken" [3]

Figure 3 shows essential components of a passing lane.

\subsubsection{Net Passing Opportunity}

Net passing opportunity concept is used to determine the need for a passing lane. This is a measure of supply of passing demand. Net passing opportunity is linked to gaps in the opposing traffic stream and percentage of passing zones. Gaps in the opposing traffic stream are a function of Average Annual Daily Traffic (AADT) of the road segment considered. If the AADT is high the gaps in the opposite direction is low and there will be less passing opportunities. 
Passing opportunities also depend on the passing zones available in the road section. Basically, passing zones considered in this context are the sections designated by the pavement markings. Thus, passing zones represent the total length of the road sections having adequate sight distance for passing. Net passing opportunity can be expressed mathematically as follows.

$\mathrm{NPO}=\mathrm{P}(\mathrm{GAO})^{\star}(\% \mathrm{PZ})$

Where,

$\mathrm{NPO}=$ Net Passing Opportunity

$\mathrm{P}(\mathrm{GAO})=$ Percentage of the hour with gaps greater than 30 seconds for passing.

$\% \mathrm{PZ}=$ Percentage of the road segment where passing is allowed by pavement markings.

Generally, passing lane is warranted if NPO is less than $30 \% .[8]$

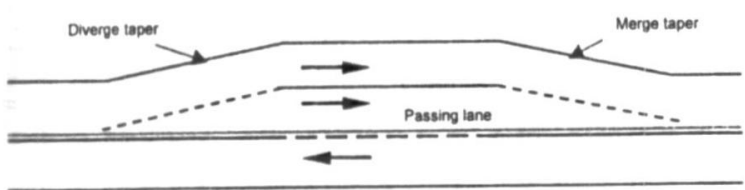

Figure 3. Essential Components of a Passing Lane

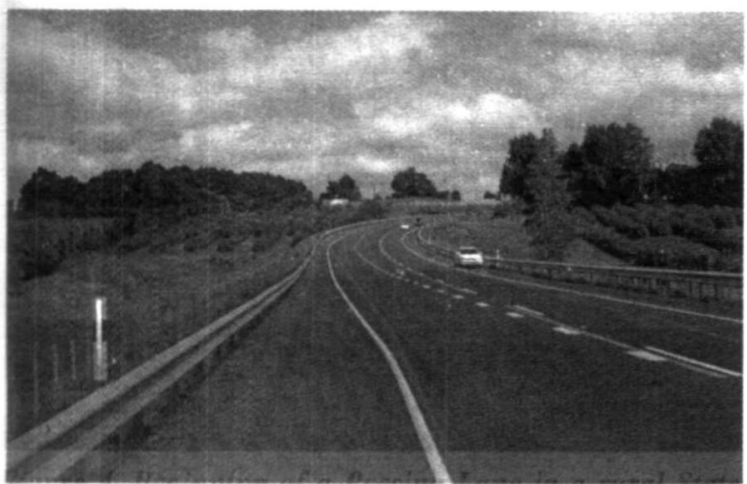

Figure 4. Beginning of a Passing Lane in a rural State Highway in New Zealand

\subsubsection{Operational Effects of a Passing Lane}

Passing lanes can reduce injury and accidents significantly by reduced driver frustration resulting from improved passing opportunities. Effects of passing lanes extend beyond the length of the passing lane. A length that has the effects of a passing lane is termed as effective length. Spot Percent Platooned (SPP) is a measure of platooing at a given point. SPP is reduced over the effective length beyond the end of the passing lane depending on downstream conditions. The concept of "percent time spent on following" can also be represented as "spot percent platooned"

Figure 5 shows the operational effects of a passing lane in terms of the percent time spent on following with respect to the position along the road. When there is less or no passing opportunities, vehicles have to follow a slow headway vehicle. Ultimately the gaps between the vehicles would reduce to form a "bunch" or "platoon".

The length of a passing lane can vary between $0.8 \mathrm{~km}$ and $3.2 \mathrm{~km}$ [8]. Passing lane lengths in the order of 1.5 to $2 \mathrm{~km}$ will provide sufficient opportunity for most queues formed behind a slow vehicle to overtake it and disperse [3]. In general, a spacing of 10 to $15 \mathrm{~km}$ or approximately 10 minutes travel time is adequate in a $100 \mathrm{~km} / \mathrm{h}$ speed environment to provide sufficient passing opportunity. Optimum design length of a passing lane depends on the vehicle flow rate.

Table 1. Optimum Design Lengths of Passing Lanes

\begin{tabular}{|c|c|}
\hline Flow Rate (veh/hr) & Length $(\mathrm{km})$ \\
\hline 100 & 0.8 \\
200 & $0.8-1.2$ \\
400 & $1.2-1.6$ \\
700 & $1.6-3.2$ \\
\hline
\end{tabular}

Source: ( John Morrall, 2003)

As shown in Figure 5, the effects of a passing lane are extended beyond the passing lane itself. Percent time spent on following rises sharply within a short distance after the end of the passing lane and then gradually rises to the original condition over a length of about $8 \mathrm{~km}$. Within the effective length of a passing lane, gaps between vehicles are longer and thus there are improved passing opportunities. Towards the end of the effective length platoon formation commences again and continues until the next passing lane.

\subsection{Climbing Lanes}

The principal difference between a climbing lane and a passing lane is that the former is located on a long and steep uphill grade 


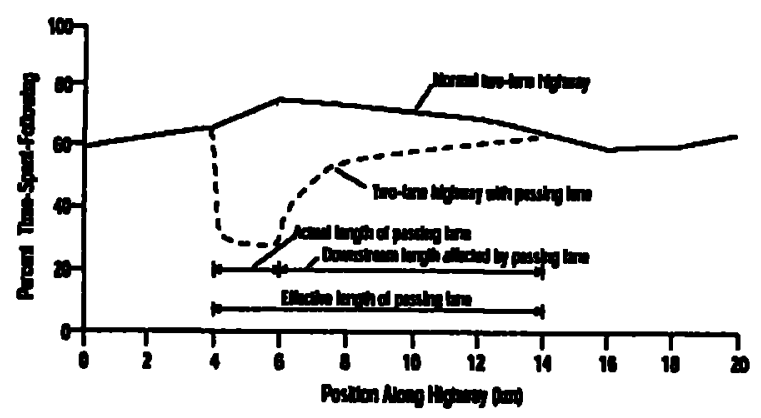

[Source: Highway Capacity Manual, 2000]

Figure 5. Operational Effects of a Passing Lane

whereas the latter is located in a flat section, in which delays are not mainly due to trucks Climbing lanes are provided in order to overcome delays caused by heavy vehicles and to improve passing opportunities. Speed differences in steep uphill grades are much greater than on level sections. Apart from those differences, climbing lanes can be treated in the same way as passing lanes, both forms considered as auxiliary lanes.

Truck speeds in steep uphill grades drop considerably causing other vehicles to follow them in rural two lane highways. Adverse effects of slowing down of trucks depend on the grade and the length of the climb. In steep, long climbs heavy trucks characterise a gradual drop of speed typically to $40 \mathrm{~km} / \mathrm{h}$ [1] and start crawling. This situation causes fast moving vehicles demanding increased opportunities for overtaking. This is phenomenal when the gaps in the opposing direction are less, combined with adverse horizontal alignments.

When a vehicle is forced to deviate more from the average speed, chances of involving it in an accident are much higher. According to State Highway Geometric Design Manual (SHGDM) New Zealand, a maximum tolerable speed reduction of $15 \mathrm{~km} / \mathrm{h}$ should be used for design purposes.

Truck entry speed and the mass to power ratio are key factors associated with the design truck that is considered in climbing lane warrants. American Association of State Highway and Transportation Officials (AASHTO) warrants a climbing lane wherever speed of a $300 \mathrm{lb} / \mathrm{hp}$ $(180 \mathrm{~g} / \mathrm{W})$ truck is reduced by $10 \mathrm{mph}(16 \mathrm{~km} / \mathrm{h})$ or more and the volume and percentage of heavy trucks justify the added cost [4]. New Zealand adopts $5 \mathrm{~kW} /$ tonne as the standard truck in determining climbing lane lengths [3].
Figure 6 shows truck performance curves adopted in New Zealand State Highway designs. Length of climb, \% grade and the traffic volume are other attributes that are considered in determining the need of climbing lanes. Climbing lanes are provided even for roads with low traffic volumes in special circumstances such as long grades over $\mathbf{8 \%}$. Significant proportion of accidents is attributable to congestion resulting from slow moving vehicles and presence of industry generating heavy trucks [1].

\subsection{Short four lane sections}

Providing short four lane sections is the best option for passing improvement in two lane sections. However, this option is applicable in sections where there are high traffic volumes that will establish economic justification. Four laning short sections can be considered as the initial stage of a future road upgrading project.

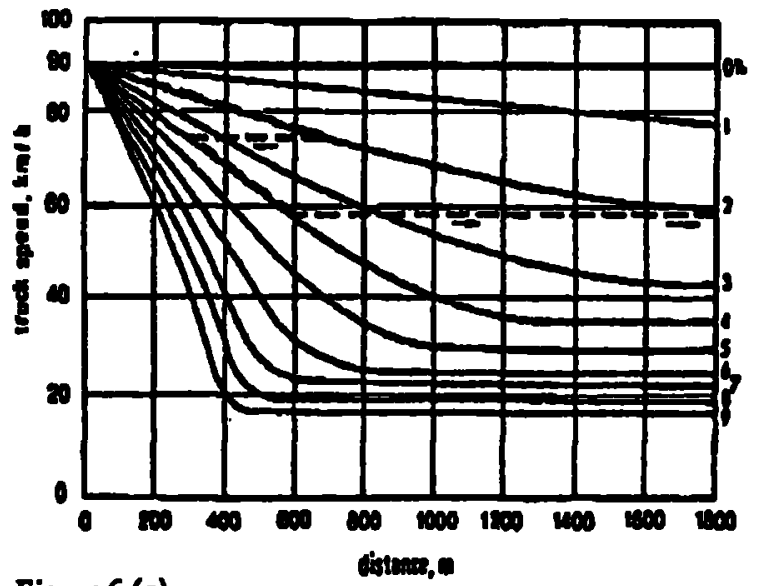

Figure $6(a)$

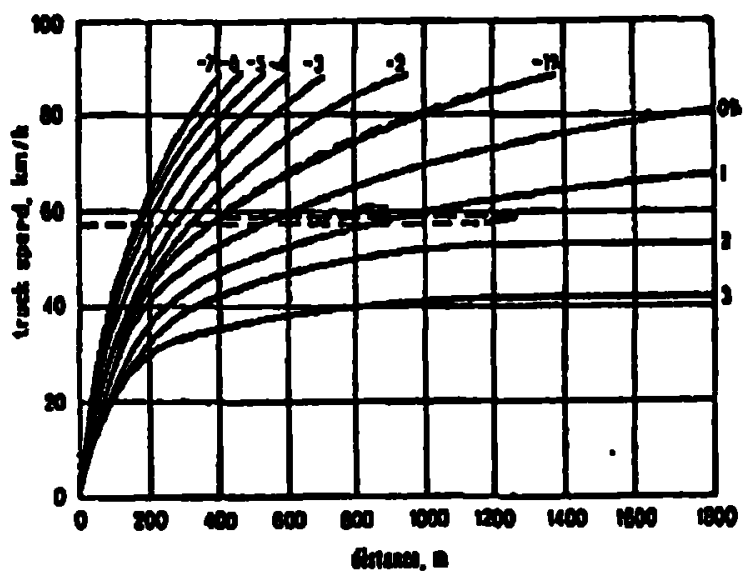

Performance Cures for 5 kW/Tone Trueks on Downgrades

Figure 6 (b)

[Source: Draft State Highway Geometric Design Manual (2003)] 
This will be an added advantage for a future road widening project. This will provide opportunities for monitoring performance in widened sections in terms of safety and traffic operations prior to undertaking full scale development. Short, four lane section can be undertaken as a pilot project of a major four laning projects.

Traffic operation wise, there are some differences between staggered passing lanes and short four lane sections. Short four lane sections can be located where there are no constraints to accommodate sufficient road width. It is usual to provide a centre median in a four lane section which enhances traffic safety against head on collisions. Unlike in passing lanes, opposing traffic in four lane sections has no chance of using overtaking lanes. Where there is an ample road reserve, the spacing between two carriageways can be increased to provide a sufficient clear zone in the middle. Typical median width allowed varies between $5 \mathrm{~m}$ and $10 \mathrm{~m}$. In constrained situations median barriers are to be provided to protect vehicles running off the opposing carriageway. When such conditions exist short four lane sections can operate under express way environment. These conditions have remarkable effects on the mobility of the entire road, increased Average Travel Speed, reduced Average Travel Time, reduced driver frustration and increased safety. This also provides long-term economic benefits on the capital investments made in the early stages of a four laning project.

\section{Minor Passing Improvements}

Minor passing improvements address mainly localised improvements of passing opportunities in road segments with very low traffic volumes. Such improvements are turnouts, shoulder driving and shoulder used sections.

\subsection{Turnouts}

Turnouts are a shorter version of passing lanes, provided for roads having very low traffic volumes typically less than 2000 AADT. Lengths of turnout are normally kept between 60 and $180 \mathrm{~m}$, which can be extended up to $300 \mathrm{~m}$ according to New Zealand standards. This compares with the minimum requirement of
$800 \mathrm{~m}$ for passing lanes. The purpose of turnouts is to provide space for slow moving vehicles to pull aside and stop, if required, letting the following vehicles to overtake them.

It is not common for trucks using turnouts. Turnouts cannot accommodate passing opportunities for long platoons. In New Zealand practice, turnouts are mostly used by recreational vehicles. Therefore turnouts are mainly provided in tourist routes having scenic beauty and in coastal areas. Consideration must be given in road sections having a higher proportion of recreational vehicles but low AADT, to provide turnouts.

Care must be taken to provide adequate sight distance at the beginning and the end of turnouts. They should not be ended up abruptly. Vehicles exiting from a turnout should have a clear view of the vehicles coming behind. Providing a series of turnouts at regular intervals will be more effective in providing passing opportunities. It is dangerous to provide turnouts in left hand horizontal curves. But in contrast, locating turnouts in right hand horizontal curves with adequate sight distances, have advantages for passing vehicles so that they have to follow a shorter path and have good visibility between vehicles. Turnouts should not be provided in the vicinity of parking and rest areas. Turnouts should be clearly distinguished between service facilities.

\subsection{Shoulder Driving}

Shoulder driving is another low cost option, which improves passing opportunities. This is applicable only in very low traffic conditions. The concept behind shoulder driving is, slow moving vehicles move on to paved shoulder to allow for passing of faster vehicles. This can be considered as an extended turnout.

The question of whether the shoulder is strong enough or wide enough to accommodate slow vehicles needs to be addressed. Generally, slow vehicles are 'heavy' comprising trucks, buses, recreational vehicles and farm vehicles. The damaging effect of a heavy vehicle increases by the fourth power of the ratio of axle loads to that of a passenger car. Economic life of pavement depends on the cumulative standard axle loads which is a function of both AADT and traffic composition. Therefore AADT and heavy 
vehicle composition are major factors that determine the cost effectiveness of shoulder driving.

Shoulder driving requires the width of the shoulder to be the same as that of a traffic lane. Cost of the wider shoulder that is required for vehicle passage should be compared with the width that would otherwise have been required. Shoulder driving imposes a potential danger to other road users such as cyclists and. pedestrians.

Shoulder driving applications vary depending on the policy requirements of different controlling authorities. Shoulder driving is becoming increasingly popular in Texas, Alberta and Sweden [8]. Substantial improvements can be achieved by allowing shoulder driving while reducing accidents and safety problems.

In the Sri Lankan context narrow shoulders can be utilised for trishaw travelling. Three wheel taxis have become a popular transport mode among the general public in our country. However the adverse impact on the efficiency of transport network in terms of slow speeds and horrific manoeuvres is overwhelming. Reasonably narrow shoulders can be used for trishaws to mitigate this problem.

Shoulder driving requires disciplining undesirable driver behaviours particularly against other shoulder users.

\section{Localised Realignments}

Localised realignments address the operational and safety problems associated with specific curve locations rather than a segment of a road. Most of the severe injury accidents in rural two lane highways are caused by visibility problems in curves.

Ancient roads followed an evolutionary path from horse tracks to cart tracks, then to gravel roads and finally to paved carriageways catering for the whole gamut of vehicular traffic. In this evolutionary process much of the considerations have been diverted for upgrading from one stage to the other within the funding constraints, without planning ahead. Therefore it is evident that a significant portion of rural roads do not satisfy design standards that are applied to new roads.
Localised realignments are mainly aiming at improved visibility of the problem location. These are considered in sharp horizontal curves, reverse horizontal curves, crest and sag vertical curves and any combination. In addition realignments need to address specific turning paths of long vehicles like log hauling trucks and stability of heavy vehicles against sliding and overturning. Localised realignments shall not be considered in isolation of road needs. It is very important to consider the interaction of such improvements with the surrounding environment and social issues. Adaptability of the proposed design must be thoroughly checked with the existing features such as;

- providing access to road side properties;

- relocation of underground service appurtenances (need extensive site investigations);

- storm water drainage;

- effects on livelihood of the residents;

- effects on the cultivation in the area;

- environment protection, marine lives; and

- hydrological studies and impediments on upstream settlements and cultivations;

Designers must have a holistic approach rather than the technical needs of the road alone. Effects on all the factors must be translated into cost terms and the implementation of improvement must be driven by a benefit cost analysis. Technical viability and economic feasibility are key factors that must be considered in making any decision.

Above all, community consultation must be a major link in any alteration of status quo. Sad to say, our design practices overlook this aspect and pay little or no consideration for community consultation during the design stage, leaving surprises to take place at the construction stage.

\section{Turning Improvements}

Background to turning improvements is similar to that of localised realignments considered in section 5 above, in respect of the evolutionary path of rural roads. Apart from that, collision mitigation measures and improvement of traffic operations are driven by continuous accident monitoring of intersections. Furthermore, turning of log haul trucks and long combined 
trucks is a major problem as far as the safety and traffic operations are concerned. Major problems associated with log haul trucks are:

- swept path at intersections has a potential danger for other vehicles;

- encroachment into adjacent lanes during turning; and

- longer sight distance requirement;

Therefore special care should be taken in designing turning improvements in areas where logging trucks are in operation. Intersections that are properly designed by providing additional signage facilitate safe traffic operation in such circumstances.

\section{Effectiveness of Low Cost Countermeasures}

\subsubsection{Effectiveness of Passing Lanes and Climbing Lanes}

According to Transfund New Zealand's project evaluation manual, typically a reduction of $30 \%$ of overtaking accidents, $40 \%$ to $60 \%$ head on accidents and $15 \%$ of rear end/obstruction accidents can be expected within a passing lane. Studies in Alberta suggest 25\% [8] reduction in total accidents have been yielded by passing lanes. This shows a significant reduction in accidents can be expected from providing passing lanes on congested two lane two wayroads. Benefits of passing lanes as a low cost countermeasure in two lane two way roads are manifold. In addition to accident cost savings, travel time cost savings and vehicle operating cost savings also are considered in passing lane improvements. Of these, vehicles operating costs are minor and travel time cost savings are significant. Much of the benefits are resulting from accident cost savings, as injuries are expensive to the nation. Furthermore, driver frustration is valued on the basis of willingness to pay.

Severity of crashes in hilly areas can be higher than in the level sections. Probability of vehicles running off the road due to driver frustration in mountainous terrain is much higher. Consequences in such movements of vehicles are disastrous. On the other hand, the likelihood of head on collisions is also much higher in mountainous terrains, firstly due to less passing zones and secondly due to the rate of acceleration in an ascending grade being lesser, requiring increased time for overtaking manoeuvre. Therefore benefits from accident reduction in climbing lanes are greater than those of passing lanes.

\subsubsection{Effectiveness of Turnouts}

Turnouts are very effective in low traffic volumes and facilitate enhanced safety and operation of vehicles. Properly designed turnouts provide $20 \%$ to $50 \%$ passing of a $2 \mathrm{~km}$ passing lane [8]. Past practice shows that there are no safety problems associated with turnouts.

Providing adequate lane width, proper signs and pavement markings can increase effectiveness of turnouts.

\subsection{New Zealand Experience and the Effectiveness}

For the success of safety and traffic operation, design of proper road infrastructure alone will not be sufficient. Implementation of traffic regulations should equally take place. In this respect, functions of Land Transport Safety Authority (LTSA) are immense. LTSA is mainly focussing on the regulation of driver behaviour. More emphasis is given to the regulatory aspect rather than physical characteristics of roads. LTSA is mainly dealing with:

- promoting improvements in the road environment;

- ensuring compliance with safety standards;

- providing safety information and advice and fostering education programmes;

- conducting regular reviews of both rail and road systems;

- investigating and reviewing land transport accidents and incidents; and

- creating and managing information databases on road user charges, vehicle licensing and registration, driver licensing[6].

These functions are being carried out with a greater responsibility, operations are monitored regularly and corrective actions are in place. This is evident from the monthly news bulletin "road safety", where focus is mainly on disciplining drivers in the areas of high speed driving, alcohol consumption, log truck driver 
behaviour, holiday season driving, school children safety etc.

\subsubsection{Crash Statistics}

Reduction in road accidents is a good indicator of the effectiveness of countermeasures. By implementing safety measures over the last 10 to 15 years New Zealand has achieved substantial improvement in road safety. But there is still more to achieve in reduction of injury accidents.

Table 2 shows the fatal crashes recorded within the whole country from year 1997 to 2005 suggesting a reduction from 539 to 405 Road deaths per year. This is a remarkable reduction with the ever increasing population and vehicles

Table 3 shows the reported road accident deaths in Sri Lanka from 1996 to 2000. It is interesting to note that the annual road deaths per 10,000 vehicles was dropping from 2.3 to 1.3 in the last 9 years in New Zealand whereas in Sri Lanka it was settling around 12.5 .

\section{Conclusion}

Major operational problems associated with two lane two-way roads are speed differences between fast and slow moving vehicles and turning delays of vehicles. Because of the speed difference between slow and fast moving vehicles, the drivers who need to travel fast become frustrated. Driver frustration leads to serious road accidents. There are many low cost countermeasures being adopted in many countries.

Among the low cost countermeasures, passing lanes and climbing lanes are of paramount importance as their effectiveness is tremendous.

Other countermeasures are short four lane sections, turnouts, localised realignments, shoulder driving and intersection improvements. Though short four lane sections are ideal, they are more costly than passing lanes and may not be feasible in most cases. The impact of short realignments and improvement of intersections are remarkable.

In Sri Lankan context narrow shoulders could be used for trishaw movements to improve the efficiency of the transport network.

Experiences from New Zealand and Canada show passing lanes and climbing lanes are contributing to a reduction of crash accidents by $25 \%$ to $30 \%$ [8].

The Sri Lankan road network is getting congested rapidly than ever. Introduction of low

Table 2. Road Fatalities in New Zealand

\begin{tabular}{|l|l|l|c|c|c|c|c|c|c|}
\hline \multicolumn{1}{|c|}{ Year } & 1997 & 1998 & 1999 & 2000 & 2001 & 2002 & 2003 & 2004 & $2005 \cdot$ \\
\hline $\begin{array}{l}\text { Number of } \\
\text { Road Deaths }\end{array}$ & 539 & 501 & 508 & 462 & 455 & 405 & 461 & 435 & 405 \\
$\begin{array}{l}\text { Deaths/ } \\
10,000 \text { vehicles } \\
\text { Deaths/ } \\
100,000\end{array}$ & 2.3 & 2.1 & 2.0 & 1.8 & 1.7 & 1.5 & 1.6 & 1.5 & 1.3 \\
\hline
\end{tabular}

[Source: LTSA]

Table 3. Road Fatalities in Sri Lanka

\begin{tabular}{|l|c|c|c|c|c|}
\hline \multicolumn{1}{|c|}{ Year } & 1996 & 1997 & 1998 & 1999 & 2000 \\
\hline $\begin{array}{l}\text { Number of } \\
\text { Road Deaths }\end{array}$ & 1660 & 1753 & 2023 & 2058 & 2150 \\
$\begin{array}{l}\text { Deaths/ 10,000 } \\
\text { vehicles }\end{array}$ & 12.5 & 12.5 & 13.4 & 12.7 & 12.6 \\
$\begin{array}{l}\text { Deaths/ 100,000 } \\
\text { People }\end{array}$ & 9.5 & 9.9 & 11.3 & 11.3 & 11.6 \\
\hline
\end{tabular}

[Source: Dharmaratna \& Stevenson] : 
cost countermeasures will ease this problem to some extent. By considering road fatalities in the year 2000 in Sri Lanka, 25\% reduction means saving $\mathbf{5 5 0}$ valuable lives to the nation every year.

\section{References:}

1. Austroads (1999) Guide to the Geometric Design of Ruml Roads, Sydney, Austrmlia

2. Dharmaratne Samath D, Stevenson Mark Rond Fatalities in Sri Lanka: 1980 to 2000,

3. Draft State Highway Geometric Design Manual (2003) Transit New Zealand, Wellington, New Zenland

4. Highway Capacity Manual (1994) Transportation Research Board, National Research Council Washington.

5. Highway Capacity Manual (2000) Transportation Research Board, National Research Council Washington

6. http://www.ltsa.govt.nz/

7. Manual of Traffic Signs and Markings (1998) Transit new Zealand, Wellington, New Zealand and Land Transport Snfety Aufhority Wellington, New Zenland

8. Morrall. J,(2003) Course materials, Highway Safety and Operations, University of Auckland, Auckland, New Zealand.

9. Project Evaluation manual (2002) Transfund New Zenland, Wellington, New Zenland. 